\title{
ASPECTOS GERAIS DA SITUAÇÃO DE LAVRA PARA GRANITOS ORNAMENTAIS NO MUNICÍPIO DO RIO DE JANEIRO
}

\author{
João Baptista Filho \\ Aline T. Silva \\ Dept $^{\circ}$ de Geologia
}

\begin{abstract}
Rio de Janeiro is one of the most important producers of ornamental granites in Brazil. Environmental laws and tributary taxes have been a major hazard to mining activities, in a profitable way, making the miner's production decrease considerably. It is now important a development of a new political attitude towards a better improvement of the exploration.
\end{abstract}

\section{Situação do Problema}

O Estado e o Município do Rio de Janeiro possuem uma grande vocação para o aproveitamento de bens minerais não-metálicos, incluindo-se ai as rochas ornamentais, onde o Estado e, principalmente, o Município do Rio de Janeiro, possui uma grande variedade destas. Tais jazidas, com destaque para aquelas localizadas na área urbana da cidade do Rio de Janeiro, apresentam todo o tipo de problema para sua lavra, tais como:
a) altos custos
b) desmatamento
c) assoreamento de leitos fluviais
d) destruição da paisagem natural
e) rejeitos de um modo geral

São os problemas ambientais uma das causas mais conflitantes entre empresas mineradoras e a sociedade, levando, em certos casos, a paralisação de várias atividades de mineração de rochas ornamentais.

O Municipio do Rio de Janeiro, em particular, vem enfrentando nos últimos dez anos, um grande aumento no número de pedreiras fechadas por ordem da Secretaria de Obras do Municipio. Este fechamento está baseado no Código Civil Municipal, que proibe a exploração mineral acima da cota dos $100 \mathrm{~m}$, principalmente dentro de áreas urbanizadas. Estas restrições, a princípio, tem como objetivo a prevenção de problemas ambientais, como os acima citados, 
mormente àqueles que dizem respeito à instabilidade das encostas. Também não existe, para todo o Estado, uma politica mineral para o setor de rochas ornamentais.

São produzidos no Municipio do Rio de Janeiro, vários tipos de granitos, conforme tabela que se segue:

\begin{tabular}{|l|l|}
\hline LOCAL DE OCORRÊNCIA & MATERIAL COMERCIAL \\
\hline Alto da Tijuca & Granito Preto Tijuca \\
Campo Grande & Granito Cinza Grafite \\
Serra do Mendanha & Granito Ás de Paus \\
Alto da Tijuca & Granito Ouro Velho \\
Jacarepaguá & Granito Ouro Velho \\
Quintino & Granito Juparaná \\
Barra da Tijuca & Granito Sorimã \\
Bangu & Granito Amarelo Bangu \\
Campo Grande & Granito Amarelo Bangu \\
Serra do Mendanha & Granito Cinza Azul \\
& Granito Guanabara \\
\hline
\end{tabular}

Como pode ser visto, é grande o número de rochas ornamentais que possui o Municipio que já foi o detentor de $80 \%$ da produção estadual (DNPM, 1988). Porém com o advento das leis conservacionistas, esta produção caiu drasticamente. Estão ativas atualmente somente as jazidas situadas em áreas mais remotas (Campo Grande, Bangu, Jacarepaguá, Serra do Mendanha), enquanto aquelas localizadas em regiões de parques nacionais, estaduais ou municipais encontram-se completamente desativadas.

\section{Aspectos Geológicos}

O termo "granito", para fins comerciais, è toda rocha não calcária capaz de ser polida e usada como revestimento. São, principalmente, aquelas rochas plutônicas de granulação grosseira, sem distinção petrográfica distinta, incluindo-se ai granitos, gabros, dioritos, granodioritos, monzonitos, sienitos e charnoquitos.

Situado dentro de um contexto geológico conhecido como "Complexo do Litoral Fluminense", o Municipio é formado por associações gnáissico-migmatiticas, intercalados com quartzitos e rochas granitóides, posteriormente intrudidas por rochas alcalinas e básicas. 
Este conjunto leva à uma configuração morfológica tipica, favorecendo através de seus membros igneos (granitóides, alcalinas e básicas) um farto potencial de exploração, em pedreiras ou campos de matacões, de rochas ornamentais.

\section{Lavra}

Uma caracteristica da exploração de rochas ornamentais no Municipio do Rio de Janeiro, se dá condicionada à lei da cota dos $100 \mathrm{~m}$. Em função dos aspectos morfológicos de nossos morros, é justamente abaixo deste limite de cota que se acumulam grandes depósitos de tálus (campos de matacões), dos quais as companhias mineradoras extraem os blocos para comercialização. Por outro lado, é também mais econômico extrair blocos de matacões do que investir em equipamentos mais sofisticados para lavra em maciços rochosos. É por estes motivos que as principais mineradoras extraem seu material comercial destes campos de matacões, utilizando equipamentos e infra-estrutura ainda bastante rudimentares, com poucos ou quase nenhum estudo preliminar para uma devida avaliação técnico-econômico-financeira do depósito

Os matacões constituem porções individualizadas de um maciço rochoso, com uma forma arredondada caracteristica fornecida pelo processo conhecido como esfoliação esferoidal, muito comum na paisagem do Rio de Janeiro, onde predominam rochas granitóides e alcalinas( que são favoráveis a formação desse tipo de estrutura). Do ponto de vista da lavra os matacões devem ter dimensões apropriadas e quantidades suficientes para produzir um bom número de blocos.

Para o caso do Rio de Janeiro são consideradas duas medidas ideais de blocos:

$$
\begin{aligned}
& 2,6 \mathrm{~m} \times 1,4 \mathrm{~m} \times 1,4 \mathrm{~m}-\text { blocos pequenos }( \pm 15 \mathrm{t}) \\
& 3,0 \mathrm{~m} \times 2,0 \mathrm{~m} \times 1,7 \mathrm{~m}-\text { blocos grandes }( \pm 27 \text { à } 20 \mathrm{t})
\end{aligned}
$$

Tais dimensões são compativeis para atender a capacidade dos teares e das balanças rodoviárias.

O processo de esquadrejamento dos matacões é feito através do uso de pólvora negra, marteletes e cunhas individuais, obedecendo-se à um procedimento padrão. Uma vez isolados, os blocos são vendidos para as serrarias (que podem ou não pertencer à mineradoras). Mas na sua grande maioria são comercializados no estado bruto ao invés de acabados (chapas). A 
preferência pela comercialização no estado bruto se dá por diversos fatores: melhor preço do material no mercado externo; redução nos custos de produção; riscos de perda de material e equipamentos; desigualdade de concorrência no mercado externo. A produção de chapas acabadas atende, basicamente, ao mercado interno.

A falta de estudos geológico-econômicos adequados das jazidas, leva à uma quase improvisação dos métodos de lavra e avaliação da qualidade estética do material. Quando muito é feito um mapeamento geológico bem simples, análise petrográfica imediata e, quando possivel, se necessário, furos de sondagem ou métodos geofisicos. Nem sempre uma cubagem precisa e ensaios mecânicos são realizados. Na sua grande maioria a avaliação das rochas é feita com base em critérios puramente estéticos, tais como: cor no estado seco e úmido, padronagem e uniformidade da textura. Tais procedimentos são comuns no Municipio do Rio de Janeiro, tendo em vista o grande número de campos de matacões e seguem, em sua grande maioria, o seguinte esquema:

1) Seleciona-se um matacão de dimensões suficientes para cortar alguns blocos.

2) Faz-se o desaterramento (se necessário).

3) Destaca-se uma porção do matacão com auxilio de explosivos.

4) Avalia-se a qualidade estética do bloco (às vezes por simples comparações) e explora-se ou não a jazida.

O impacto ambiental é bastante desconsiderado uma vez que, a grande maioria das jazidas, ainda em exploração, estão localizadas em áreas já previamente desmatadas (antigos sitios e fazendas) e longe de cursos de água de uso direto para a população. Algumas mineradoras para evitar a estocagem de rejeitos, reaproveita as sobras na fabricação de paralelepipedos. E mais ainda, combinam com os moradores locais mais próximos, a hora em que poderão dar o "fogo" para desmonte dos blocos, evitando com isto surpresas desagradáveis aos vizinhos.

Baseado nas premissas acima citadas, as empresas mineradoras acham-se desobrigadas de apresentar relatórios de impacto ambiental, em desacordo com os órgãos governamentais.

A falta de comunicação entre a FEEMA; o IBAMA e empresas mineradoras leva à uma série de entraves no desenvolvimento da lavra. A fiscalização não é devidamente feita $\mathrm{e}$, em muitas vezes, as mineradoras tomam atitudes imediatistas e remediáveis para escapar de multas e sanções. 


\section{Considerações Finais}

O Estado do Rio de Janeiro é o oitavo maior produtor de rochas ornamentais do pais, e o Município do Rio de Janeiro, o maio produtor do Estado (Tabelas 1 e 2).

É fato conhecido que muitas informações geológicas, técnicas e financeiras são desconsideradas, dificultando o dimensionamento apropriado dos investimentos para lavra por faltarem subsidios que auxiliem no planejamento do volume de produção e método de lavra. Isto traz, como conseqüência, o aumento no grau de risco do empreendimento prejudicando a determinação da taxa real de retorno econômico financeiro dos projetos.

São inúmeros os problemas que levam à uma quase estagnação da produção de granitos ornamentais no Municipio do Rio de Janeiro, a começar pelo grave entrave ambiental enfrentado pelas empresas do setor. Soma-se à isto a ausência de tecnologia na maior parte das empresas e a politica tributária do Estado.

Apesar de tudo, segundo dados do DNPM, o Município do Rio de Janeiro ainda é o maior produtor de blocos brutos de granito ornamental. Isto mostra onde uma politica ambiental e tributária melhor conduzida e a racionalização dos projetos de lavra e beneficiamento, poderá atrair maiores recursos de capital para o setor de rochas ornamentais, tornando o Municipio mais competitivo nos mercados interno e externo.

Tabela 1 - Produção Estimada de Rochas Ornamentais por Estados.(*)

\begin{tabular}{|l|c|c|c|}
\hline \multicolumn{1}{|c|}{ Estado } & Ano & Granito $\left(\mathrm{m}^{3}\right)$ & Total \\
\hline Espirito Santo & 1990 & 120.000 & 120.000 \\
Minas Gerais & 1993 & 133.000 & 133.000 \\
Bahia & 1992 & 36.000 & 36.000 \\
São Paulo & 1990 & 54.000 & 54.000 \\
Ceará & 1992 & 36.000 & 36.000 \\
Rio Grande do Sul & 1991 & 29.000 & 29.000 \\
Paraná & 1990 & 13.200 & 13.200 \\
Rio de Janeiro & 1990 & 12.800 & 12.800 \\
\hline
\end{tabular}


Tabela 2 - Produção de Granito Ornamental no Estado do Rio de Janeiro.(*)

\begin{tabular}{|l|r|r|r|r|r|r|r|r|}
\cline { 2 - 9 } \multicolumn{1}{c|}{} & \multicolumn{4}{c|}{ Produção $1992\left(\mathrm{~m}^{3}\right)$} & \multicolumn{3}{c|}{ Produção $1995\left(\mathrm{~m}^{3}\right)$} \\
\hline \multicolumn{1}{|c}{ Municipio } & Mina & Usina & \multicolumn{1}{c|}{ Total } & \multicolumn{1}{c|}{$\%$} & Mina & Usina & \multicolumn{1}{c|}{ Total } & \multicolumn{1}{c|}{$\%$} \\
\hline Bom Jardim & 90 & - & 90 & 0,7 & 0,0 & 0,0 & 0,0 & 0,0 \\
Magé & 481 & 2304 & 2785 & 20,4 & 0,0 & 0,0 & 0,0 & 0,0 \\
Nova Iguaçu & - & - & 0,0 & 0,0 & 429 & 234 & 663 & 12,0 \\
Rio de Janeiro & 6305 & 4439 & 10744 & 78,9 & 2686 & 2195 & 4881 & 88,0 \\
\hline Total do Estado & 6876 & 6743 & 13619 & 100,0 & 3115 & 2429 & 5544 & 100,0 \\
\hline
\end{tabular}

(*) Fonte: DNPM/RJ - Setor de Economia Mineral.

\section{Bibliografia}

BAPTISTA $F^{2}$, J. - Subsidios para uma politica de desenvolvimento do setor de rochas ornamentais no Estado do Rio de Janeiro. Tese de Doutoramento (Programa de PósGraduação em Geologia - IGEO/CCMN/UFRJ) - em andamento

BRASIL - DNPM - Anuário Mineral Brasileiro. MME, Brasilia. 1991

BRASIL - DNPM - Principais Depósitos Minerais do Brasil. MME, Brasilia. 1991.

CHIODI F $\mathrm{F}^{2}$, C. - Aspectos Técnicos e Econômicos do Setor de Rochas Ornamentais. CETEM/CNPq, 75 p. (Série Estudos e Documentos). 1995.

COELHO, C.M - Estudo Técnico-Econômico-Financeiro da Produção de Granitos Ornamentais no Municipio do Rio de Janeiro. Seminário de Mestrado (Programa de PósGraduação em Geologia - IGEO/CCMN/UFRJ), Rio de Janeiro. 1997. 